\title{
The 5'-Flanking Region of the Mouse Adenylyl Cyclase Type VIII Gene Imparts Tissue-Specific Expression in Transgenic Mice
}

\author{
Lisa M. Muglia, ${ }^{1}$ Michele L. Schaefer, ${ }^{4}$ Sherri K. Vogt, ${ }^{1}$ Gregory Gurtner, ${ }^{1}$ Atsuko Imamura, ${ }^{1}$ and \\ Louis J. Muglia ${ }^{1,2,3}$ \\ Departments of ${ }^{1}$ Pediatrics, ${ }^{2}$ Molecular Biology and Pharmacology, and ${ }^{3}$ Obstetrics and Gynecology, Washington \\ University School of Medicine, St. Louis, Missouri 63110, and ${ }^{4}$ Neurosciences Program, University of Colorado Health \\ Sciences Center, Denver, Colorado 80262
}

The calcium-stimulated adenylyl cyclases (ACs) play a central role in stimulus-dependent modification of synaptic function. The type VIII AC (AC8) is one of three mammalian calciumstimulated isoforms, each of which is expressed in a regionspecific manner in the CNS. To delineate the DNA sequences responsible for appropriate targeting of AC8 expression, we report here the complete structure of the AC8 gene and define the pattern of expression of the full-length cDNA and its splice variants. In addition to expression within the brain, robust expression of AC8 was also found in the lung. By in situ hybridization, we have found the highest expression of AC8 mRNA within the olfactory bulb, thalamus, habenula, cerebral cortex, and hypothalamic supraoptic and paraventricular nuclei. By generating transgenic mice whose expression of $\beta$-galactosidase is controlled by the AC8 $5^{\prime}$-flanking DNA sequences, we demonstrate that the DNA sequences within the $10 \mathrm{~kb}$ preceding exon 1 are critical for establishment of this region-specific pattern. This spectrum of sites of production is unique to AC8 among the calcium-stimulated adenylyl cyclases and suggests nonredundant functions with other adenylyl cyclases in neuroendocrine regulation and/or behavior.

Key words: adenylyl cyclase; chromosome; gene; hypothalamus; in situ hybridization; transgenic mice
The integration of cAMP and calcium/calmodulin signaling pathways has proven to be an important mechanism by which neuronal physiology can be modified in a stimulus-dependent manner, thus imparting plasticity in subsequent responses (Cooper et al., 1995; Xia et al., 1995). Central functional components of this adaptive pathway are the calcium-stimulated adenylyl cyclase (AC) isoforms. In Drosophila, the importance of calcium-stimulated adenylyl cyclase activity has been demonstrated in the rutabaga mutant, which exhibits a defect in associative learning (Levin et al., 1992; Davis et al., 1995). In mammals, three calciumstimulated isoforms have been identified, designated types I, III, and VIII (Cooper et al., 1995; Sunahara et al., 1996). Analogous to the rutabaga mutant in Drosophila, a mouse mutant in the type I AC displays defective spatial learning and impaired hippocampal long-term potentiation (Wu et al., 1995). This finding is consistent with the observation that type I AC mRNA expression, as detected by in situ hybridization, is abundant in the dentate gyrus of the hippocampus and cerebral cortex (Xia et al., 1991). Highest expression of the type III AC is exhibited in the olfactory neuroepithelium (Xia et al., 1992), whereas the type VIII AC is unique in being the only calcium/calmodulinstimulated isoform within the hypothalamus (Cali et al., 1994; Mons and Cooper, 1994).

To date, the structure and regulatory regions for none of the

\footnotetext{
Received Oct. 20, 1998; revised Dec. 22, 1998; accepted Dec. 28, 1998.

This work was supported by grants from the National Institutes of Health, Howard Hughes Medical Institutes, and Monsanto Company, and a Burroughs Wellcome Fund Career Development Award in the Biomedical Sciences to L.J.M. We thank Dr. J. Gitlin for manuscript review, Drs. L. Levin and R. Reed for communication of unpublished data, and Drs. J. Majzoub and D. Cooper for plasmids.

Correspondence should be addressed to Dr. Louis J. Muglia, Washington University School of Medicine, Box 8116, One Children's Place, St. Louis, MO 63110. Copyright (C) 1999 Society for Neuroscience $\quad 0270-6474 / 99 / 192051-08 \$ 05.00 / 0$
}

mammalian AC genes have been reported. We have selected the type VIII AC (AC8) for analysis because of its probable role in regulation of neuroendocrine function. AC8 has been found to be brain-specific by relatively low-sensitivity Northern blot analysis (Cali et al., 1994) and degenerate PCR screening (Krupinski et al., 1992). Additionally, AC8 has been localized to discrete sites within the CNS by in situ hybridization studies (Matsuoka et al., 1992, 1994; Cali et al., 1994), although early reports may have been confounded by use of probes detecting the type I and/or type III ACs in addition to AC8 (Matsuoka et al., 1992). One important area of AC8 expression is likely to be the hypothalamus (Matsuoka et al., 1992; Cali et al., 1994), because hypothalamic membrane preparations display robust calcium-stimulated AC activity (Mons and Cooper, 1994), and the hypothalamus does not express the type I or III ACs (Xia et al., 1992, 1993; Mons and Cooper, 1994). Specific hypothalamic nuclei expressing AC8 were not defined in these studies.

To determine the DNA elements responsible for AC8 transcriptional regulation and the intron-exon structure, whose splice variants could provide additional diversity in AC8 protein structure and enzymatic properties, a detailed knowledge of AC8 gene structure is essential. Here, we report the organization of the murine AC8 gene and its overall pattern of expression. Using this information, we test the hypothesis that the $5^{\prime}$-flanking region of the AC8 gene is critical for targeting region-specific expression within the CNS of transgenic mice.

\section{MATERIALS AND METHODS}

Isolation of bacteriophage $\lambda$ genomic clones encompassing the AC8 gene. Random primer-labeled, PCR-generated fragments of the rat AC8 cDNA (Cali et al., 1994) were used to screen a murine $129 \mathrm{~Sv}$ genomic DNA library in Lambda FixII (Stratagene, La Jolla, CA) immobilized on nitrocellulose filters, with hybridization in $5 \times$ SSC $(0.75 \mathrm{M} \mathrm{NaCl}$ and 
0.075 M sodium citrate), $5 \times$ Denhardt's solution $(0.1 \%$ polyvinylpyrrolidone, $0.1 \%$ BSA, and $0.1 \%$ Ficoll, type 400$), 0.5 \%$ SDS, and $200 \mu \mathrm{g} / \mathrm{ml}$ salmon sperm DNA at $65^{\circ} \mathrm{C}$. Final filter washes were in $0.1 \times \mathrm{SSC}$ and $0.1 \%$ SDS at $65^{\circ} \mathrm{C}$. Restriction fragments of the mouse genomic clones were isolated after separation by agarose gel electrophoresis and ligated into pBluescript SKII+ (Stratagene) for further analysis. Sequencing was performed by the fluorescent dye termination method on a PerkinElmer-Applied Biosystems 373A DNA Sequencer (Foster City, CA), with chromatographic output analyzed with Sequencher 3.0 software (Gene Codes Corp., Ann Arbor, MI). Differences in sequence were scored manually. Homology comparisons used the Genetic Computer Group (Madison, WI) programs Blast, Bestfit, and Gap.

Long-range PCR. Typical reactions were performed in $50 \mu$ l of total volume containing $192 \mathrm{ng}$ of mouse genomic DNA (Novagen, Madison WI), $1 \times$ Accutaq LA buffer (Sigma, St. Louis, MO), $500 \mu \mathrm{M}$ dNTPs, 24 pmol of each primer (usually 34-mers, $\sim 50 \% \mathrm{GC}$, with an A or $\mathrm{T}$ at the $3^{\prime}$ end), and $0.5 \mu$ l of Accutaq DNA polymerase (Sigma). Typical PCR amplification conditions were an initial denaturation at $94^{\circ} \mathrm{C}$ for $1 \mathrm{~min}$, followed by $30-35$ cycles of (1) $95^{\circ} \mathrm{C}$ for $25 \mathrm{sec}$ and (2) $68^{\circ} \mathrm{C}$ for $21 \mathrm{~min}$.

Bacterial artificial chromosome library screening and analysis. DNA from a mouse genomic DNA ES cell bacterial artificial chromosome (BAC) library (Genome Systems, St. Louis, MO) was screened and amplified as described by the manufacturer. To isolate clones transducing both exons 1 and 3, BAC DNA pools were first tested by PCR using exon 1 primers. All positives were then tested with exon 3 primers.

Transcription initiation site determination by rapid amplification of $c D N A$ ends. An adult mouse brain Marathon-Ready cDNA library (Clontech, Palo Alto, CA) was used as template for 5' rapid amplification of cDNA ends (RACE). Amplification of AC8-specific sequences used one pair of nested 24 and 25 base primers $\left(200-300 \mathrm{bp} 3^{\prime}\right.$ to the mouse genomic DNA region homologous to the $5^{\prime}$ terminus of the longest human AC8 cDNA) and a second set of nested primers (AP1, AP2) included in the $5^{\prime}$ end adapter. PCR cycle parameters and reaction conditions were as specified by the manufacturer. Reactions products were visualized by electrophoresis through $1.4 \%$ agarose, excised from the gel, and purified for ligation into pBluescript SK II +. Seven independent clones from two separate amplification reactions were sequenced.

Chromosomal localization by interspecific backcross analysis. Twentyfive nanograms of genomic DNA obtained from a (C57BL/6J $\times$ SPRET/ Ei) $F_{1} \times$ SPRET/Ei interspecific backcross panel (Rowe et al., 1994) was used to PCR amplify and radiolabel a unique $743 \mathrm{bp}$ fragment from exon 1 of the mouse AC8 gene. PCR amplification, radiolabeling, and singlestrand conformation polymorphism determination on polyacrylamideglycerol gels was performed as described previously (Bae et al., 1996). Conformation polymorphisms were scored according to the characteristic electrophoretic mobility of C57BL/6J and SPRET/Ei alleles, and the results were analyzed by The Jackson Laboratory Backcross DNA Panel Mapping Resource (The Jackson Laboratory, Bar Harbor, ME) (Copeland and Jenkins, 1991; Rowe et al., 1994).

Tissue-specific AC8 $\mathrm{mRNA}$ synthesis by reverse transcription-PCR. Reverse transcription (RT)-PCR analysis used $3 \mu \mathrm{g}$ of total RNA from several CNS sites and peripheral organs purified by the guanidine-phenol method (Chomczynski and Sacchi, 1987). cDNA was synthesized from random hexamer-primed RNA by Moloney murine leukemia virus reverse transcriptase with conditions as described previously (Bae et al., 1996). PCR amplification of cDNA exploited primers known to span two introns of the AC8 gene based on our sequence analysis (AD8-f2, 5' CACACTTACCTGCAATACAGCG 3' from exon 1; AC8-rtr2, 5' GCTCGTCCTCCACATTGGTC $3^{\prime}$ derived from rat cDNA sequence in exon 3) with 25 cycles of $30 \mathrm{sec}$ at $94^{\circ} \mathrm{C}, 1 \mathrm{~min}$ at $58^{\circ} \mathrm{C}$, and $2 \mathrm{~min}$ at $72^{\circ} \mathrm{C}$. The expected 473 bp product was separated by electrophoresis on $1.2 \%$ agarose and visualized by ethidium staining, as well as hybridization to a radiolabeled probe from the same region.

To analyze the various sites of AC8 mRNA expression for alternatively spliced isoforms, $2 \mu \mathrm{g}$ of RNA from isolated brain regions, lung, and liver were reverse transcribed and then amplified for 25 cycles in three separate PCR reactions. Twenty-four-mer PCR primers were chosen to analyze all exons that could be alternatively spliced without changing the reading frame (exons $6,8,11,14,15$, and 16).

In situ hybridization analysis of AC8 gene expression within the CNS. Mice were deeply anesthetized with $1 \mathrm{ml}$ of $2.5 \%$ Avertin (Hogan et al., 1994) and then transcardially perfused with diethylpyrocarbonatetreated (DEPC) PBS, followed by $4 \%$ DEPC paraformaldehyde. Isolated brains were post-fixed in $4 \%$ paraformaldehyde for $24 \mathrm{hr}$, followed by immersion in $10 \%$ sucrose in DEPC PBS. Tissues embedded in OCT
(Sakura Finetek USA, Inc., Torrance, CA) were cut into $15 \mu \mathrm{m}$ sections on a cryostat and thaw-mounted onto Superfrost plus slides (Fisher Scientific, Pittsburgh, PA). A 909 base RNA probe complementary to exon 1 of the AC8 mRNA was radiolabeled with $\left[\alpha^{-}{ }^{33} \mathrm{P}\right] \mathrm{UTP}$ and T7 RNA polymerase and hybridized to sections at an annealing temperature of $55^{\circ} \mathrm{C}$ and most stringent post-hybridization wash in $0.1 \times \mathrm{SSC}$ at $60^{\circ} \mathrm{C}$ for $30 \mathrm{~min}$ (Simmons et al., 1989). To localize the position of the supraoptic nucleus, some slides underwent hybridization to a $\left[\alpha-{ }^{33} \mathrm{P}\right] \mathrm{UTP}$ labeled rat oxytocin antisense RNA probe. Slides were exposed for 5-21 $\mathrm{d}$ to Hyperfilm $\beta$ max (Amersham, Arlington Heights, IL) and emulsiondipped and developed after an additional 2-4 weeks for visualization of hybridizing areas.

Production of AC8 promoter-nuclear $\beta$-galactosidase transgenic mice. To generate an AC8 promoter-nuclear $\beta$-galactosidase fusion reporter gene, a $10 \mathrm{~kb}$ SalI-XhoI fragment of AC8 genomic bacteriophage $\lambda$ clone $\lambda 6$ $\left(-10 \mathrm{~kb}\right.$ of the $5^{\prime}$-flanking region through $\sim+480 \mathrm{bp}$ of the untranslated leader sequence) was ligated to SalI digested pnLacF (Bonnerot et al., 1987). The AC8 promoter- $\beta$-galactosidase reporter was excised from vector sequences by digestion with SalI plus HindIII, purified, and then injected into mouse oocytes (Hogan et al., 1994) at the National Institute of Child Health and Human Development Transgenic Mouse Development Facility (contract \# NO1-HD-5-3229) at the University of Alabama at Birmingham. Five transgenic founder lines of variable copy number were identified by Southern blot analysis of DNA prepared from tail biopsies, with subsequent genotype analysis by PCR.

$\beta$-Galactosidase histochemistry. For whole-mount staining, mice were deeply anesthetized with Avertin and transcardially perfused with $2 \%$ paraformaldehyde- $-0.5 \%$ glutaraldehyde in PBS. Brain was isolated, manually cut into $3-5 \mathrm{~mm}$ sections, and post-fixed $30 \mathrm{~min}$ in $4 \%$ paraformaldehyde. After two $30 \mathrm{~min}$ rinses, sections were stained with X-gal at $37^{\circ} \mathrm{C}$ for $16-24 \mathrm{hr}$ (Hogan et al., 1994). After staining, brains were either cut into $200 \mu \mathrm{m}$ sections on a vibratome for bright-field light microscopy or embedded in plastic and cut into $5 \mu \mathrm{m}$ sections for dark-field analysis.

\section{RESULTS}

\section{Characterization of the murine AC8 gene}

To determine the organization of the mouse AC8 gene and localize the DNA sequences responsible for its expression, we screened a murine 129 Lambda FixII genomic library using nonoverlapping segments of the rat cDNA as probes. A total of 15 independent phage clones encompassing the entire cDNA were identified. For those adjacent exons transduced by separate phage that did not overlap, long-range PCR methods were used to determine the intron sizes (Barnes, 1994). The longest intron measured by this method was $17 \mathrm{~kb}$, between exons 7 and 8 . Two introns were not amenable to long-range PCR: those located between exons 1 and 2 and between exons 2 and 3 . To determine the sizes of these introns, we isolated a mouse BAC clone containing exons $1-5$ in a $150 \mathrm{~kb}$ insert. Restriction map analysis of this BAC clone using infrequently cutting enzymes and hybridization to exon 1,2 , or 3 probes indicated $45 \pm 10 \mathrm{~kb}$ lies between exons 1 and 2, and $60 \pm 10 \mathrm{~kb}$ lies between exons 2 and 3 . The AC8 gene extended over $\sim 200 \mathrm{~kb}$ of DNA and was composed of 18 exons (Table 1; Fig. 1A). The only other AC gene whose structure has been reported is the Drosophila melanogaster rutabaga gene (Levin et al., 1992). The rutabaga gene contains 16 exons with some intron-exon boundaries (L. R. Levin and R. R. Reed, personal communication) conserved in comparison with mouse $\mathrm{AC} 8$ in the $\mathrm{C} 1 \mathrm{a}$, second transmembrane span, and $\mathrm{C} 2 \mathrm{a}$ coding regions. Three alternatively spliced AC8 mRNAs have been identified in the rat (Cali et al., 1996). Based on our gene structure, these splice variants arise from deletion of exon 8 (type C) or exon 11 (type B) (Fig. 1A).

The mouse (GenBank accession number U85021) and rat (Cali et al., 1994) cDNAs are $\sim 1 \mathrm{~kb}$ shorter than the near full-length human cDNA (Defer et al., 1994). Comparison of our mouse 


\begin{tabular}{|c|c|}
\hline Exon & Base pairs \\
\hline 1 & $*-2005$ \\
\hline 2 & 2006-2155 \\
\hline 3 & $2156-2286$ \\
\hline 4 & $2287-2398^{\dagger}$ \\
\hline 5 & $2399-2526^{\dagger}$ \\
\hline 6 & $2527-2685$ \\
\hline 7 & $2686-2956$ \\
\hline 8 & $2957-3154$ \\
\hline 9 & $3155-3255$ \\
\hline 10 & $3256-3457^{\dagger}$ \\
\hline 11 & $3458-3547$ \\
\hline 12 & $3548-3720$ \\
\hline 13 & $3721-3799$ \\
\hline 14 & $3800-3958^{\dagger}$ \\
\hline 15 & $3959-4105$ \\
\hline 16 & $4106-4198$ \\
\hline 17 & $4199-4313^{\dagger}$ \\
\hline 18 & $4314-4802$ \\
\hline
\end{tabular}

The first and last base pair of each exon are indicated, with base pair numbering according to the mouse AC8 cDNA sequence (GenBank accession number U85021). *Exon 1 spans $3 \mathrm{~kb}$ and begins at $\sim 1 \mathrm{~kb} 5^{\prime}$ to the terminus of the mouse AC8 cDNA. ${ }^{\dagger}$ Splice donor site conserved with the Drosophila rutabaga gene.

genomic sequences extending $5^{\prime}$ to the reported $5^{\prime}$ termini of the mouse and rat cDNAs with the human cDNA revealed extensive conservation of sequences through the entire $5^{\prime}$ nontranslated region of the human cDNA (data not shown). To define the $5^{\prime}$ terminus of the mouse cDNA, we performed 5' RACE of adult mouse brain cDNA. Seven independent clones with three different $5^{\prime}$ termini over a region of $\sim 140 \mathrm{bp}$ were found. This region mapped near the region homologous to the $5^{\prime}$ terminus of the human cDNA (Defer et al., 1994). No "TATA" box was present in the putative promoter region, although a consensus cAMP response element was found (Fig. $1 B$ ).

\section{Chromosomal localization of the murine AC8 gene}

In an effort to find naturally occurring mouse mutations in the AC8 gene, we performed backcross analysis using the Jackson Laboratory BSS panel (Rowe et al., 1994). The segregation patterns of the AC8 locus (Adcy8) and flanking genes or markers in 94 interspecific backcross mice typed for over 2400 loci were evaluated in this panel. An exon 1 PCR amplification product demonstrating single-strand conformational polymorphism between C57BL/6 and Mus Spretus when analyzed on polyacrylamide-glycerol gels was used to establish linkage to adjacent murine genes. Adcy 8 localized to a 2 centimorgan (cM) region of chromosome 15, $33.2 \mathrm{cM}$ from the centromere (Fig. 2), between the loci for the thyrotropin-releasing hormone receptor (Trhr) and focal adhesion kinase (Fadk).

\section{Tissue distribution of AC8 expression}

To sensitively determine the sites of AC8 mRNA expression, we performed RT-PCR analysis with gene-specific, intron-spanning primers on total RNA from several CNS sites and peripheral organs. AC8 mRNA was found throughout the brain, with robust amplification within the olfactory bulb, hypothalamus, hippocampus, brain stem, cerebellum, and cortex (Fig. 3). Surprisingly, the anticipated amplification product was also demonstrated in adult lung and at lower levels in heart, testes, adrenal, and ovary. Minimal or absent expression was found in the pancreas, liver, kidney, spleen, and thymus. Thus, similar to type II AC (Feinstein et al., 1991), expression of AC8 is not strictly brain-specific but most abundantly synthesized within the brain and lung.

To further characterize the spectrum of splice variants present in those tissues expressing the highest levels of AC8, we performed RT-PCR analysis using primers that amplified multiple exons simultaneously. In this way, we evaluated all exons capable of being deleted without altering the reading frame. Amplification of exons 5-9 (testing for deletion of exons 6 and/or 8) revealed two products in all tissues expressing AC8: one corresponding to the full-length cDNA (type A) and one corresponding to a cDNA arising from deletion of exon 8 (type C) (Fig. 4). Similarly, amplification of exons 10-12 demonstrated two products in all tissues expressing AC8: one corresponding to the full-length cDNA and one corresponding to a cDNA with deletion of exon 11 (type B) (Fig. 4). Amplification of exons 13-18 (testing for deletion of exons 14,15 , or 16) revealed no evidence of alternative splicing of this region.

\section{Localization of AC8 expression within the CNS}

To characterize AC8 expression within hypothalamic nuclei, we performed in situ hybridization. Within the hypothalamus, AC8 mRNA is found within the supraoptic and paraventricular nuclei and more diffusely in the region of the arcuate nucleus (Fig. 5). Outside the hypothalamus, we find relatively high-level expression of AC8 mRNA in the olfactory bulb, pontine nuclei, piriform cortex, and cerebral cortex (Fig. 5). Additionally, we find robust expression in the habenula and diff usely throughout the thalamus. Positive, although less intense, hybridization was found in the hippocampus, with expression primarily in the CA1 region and in the cerebellum, limited to the granule layer. No positive hybridization was found in mice made deficient for AC8 by gene targeting using our in situ probe and hybridization conditions (M. S. Schaefer, S. T. Wong, D. S. Storm, and L. J. Muglia, unpublished observations). Despite detection of AC8 mRNA in the lung using several intron-spanning primer pairs (Figs. 3, 4), we have not yet been able to visualize AC8 mRNA in the lung by in situ hybridization. This suggests a lower concentration of AC8 mRNA per expressing cell in lung than in brain.

\section{Tissue-specific expression in transgenic mice}

To test the hypothesis that the observed brain region-specific expression of the AC8 gene was determined by its $5^{\prime}$-flanking region and to develop a sensitive reporter system to facilitate in vivo assessment of physiological alterations in AC8 expression, we have generated AC8 promoter- $\beta$-galactosidase transgenic mice. These mice harbor a fusion gene consisting of $10 \mathrm{~kb}$ of AC8 $5^{\prime}$-flanking region, extending $\sim 480$ bp into the untranslated leader sequence, ligated to a nuclear $\beta$-galactosidase expression cassette (Fig. 6A). Five independent founders arose from oocyte pronuclear DNA injection, of which three proved capable of transmitting the chimeric reporter gene. All three founders that transmitted the transgene showed positive $\beta$-galactosidase histochemical staining within the CNS and absent staining in the liver and kidney. The highest level of nuclear $\beta$-galactosidase expression was demonstrated in offspring of founder 638 (Fig. $6 B-F$ ). Within the hypothalamus, expression of the transgene was readily detected in the supraoptic nucleus (Fig. 6D-F), paraventricular nucleus, and arcuate nucleus (Fig. 7). In agreement with the in situ hybridization studies, intense staining was also found in the 
A

$10 \mathrm{~kb}$

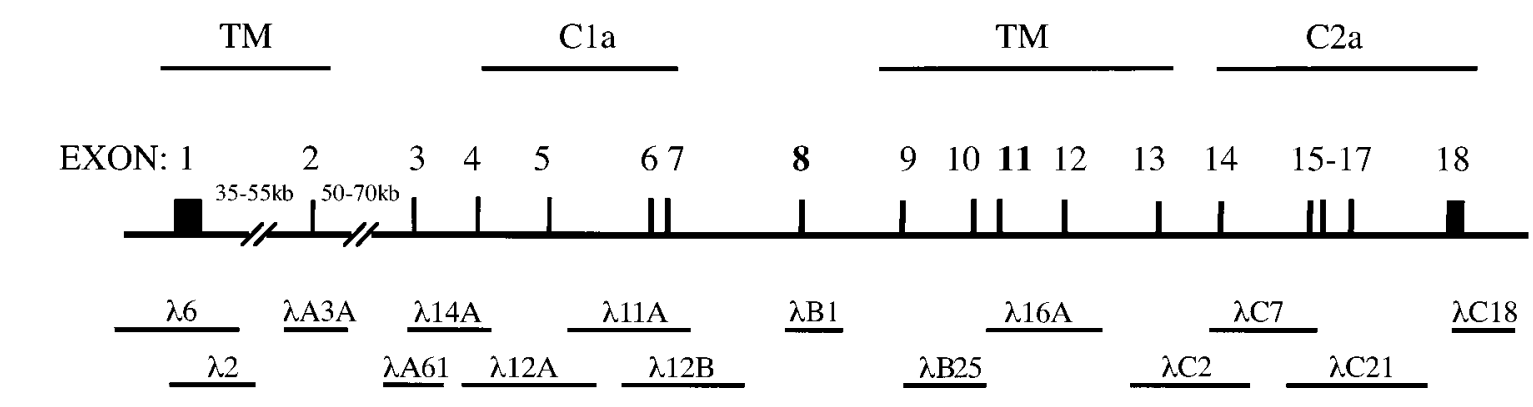

B

ggatcctcagggaaagctgtttttgcttaggaccaaaaggagctaggagtttgcactaga

agaaggcataaaaatcgccttctcggggttggggtcgggggagatagggtggggtgggg

*term. 1

gttgggaatagtgtcctggagacCGCTTGGCCAGGTCATTTAGGCTTTCATGGGACGCCG

CGGGGTTGCGAAAGCGCCCAGAGCCTGACGTCATTGACCATCAGCTGACTGTGTTTCAGG

*term. $2 * \star 5$, end human CDNA *term. 3

GCCCGAGCTTCACTGGCTGCAGCCGCAGTCGCTGTGGCAGAGGTGTTGATTTCCACCACC

TGCAGAATGGGGCTCCAGACTGGTACTGCTACCAGATCCCTGAAAAGCCAGACTCCAAGG

Figure 1. Organization of the AC8 gene. A, AC8 gene map. Exons are numbered 1-18. Bold exon numbers correspond to those alternatively spliced in the rat cDNA. The sizes of introns 1 and 2 are shown above broken lines. Exons encoding transmembrane (TM) and C1a and C2a protein segments are indicated. The individual bacteriophage clones are shown below the composite map. $B$, Determination of the $5^{\prime}$ end of the AC8 mRNA by RACE. Three different $5^{\prime}$ termini of the mouse AC8 cDNA are indicated $\left(^{*}\right)$, with the $5^{\prime}$ ends in bold. The $5^{\prime}$ end of the human cDNA (**) is also in bold. A consensus cAMP response element is underlined.

Figure 2. The mouse AC8 gene (Adcy8) maps to chromosome 15 . The segregation patterns of Adcy8 and flanking genes or markers in 94 interspecific backcross animals are shown on the left. Each column represents the chromosome inherited from the $(\mathrm{C} 57 \mathrm{BL} / 6 \mathrm{~J} \times \mathrm{SPRET} / \mathrm{Ei}) \mathrm{F}_{1}$ parent. Black boxes represent the presence of a $\mathrm{C} 57 \mathrm{BL} / 6 \mathrm{~J}$ allele, and white boxes represent the presence of a SPRET/Ei allele. The number of offspring inheriting each type of chromosome is shown below the corresponding column. A partial chromosome 15 map is shown on the right, indicating the location of Adcy 8 in relation to the linked loci for Trhr, D15Bir7, D15Mit3, and Fadk. The centromere is designated by the black circle. Distances between loci, in centimorgans, are shown to the left of the chromosome.

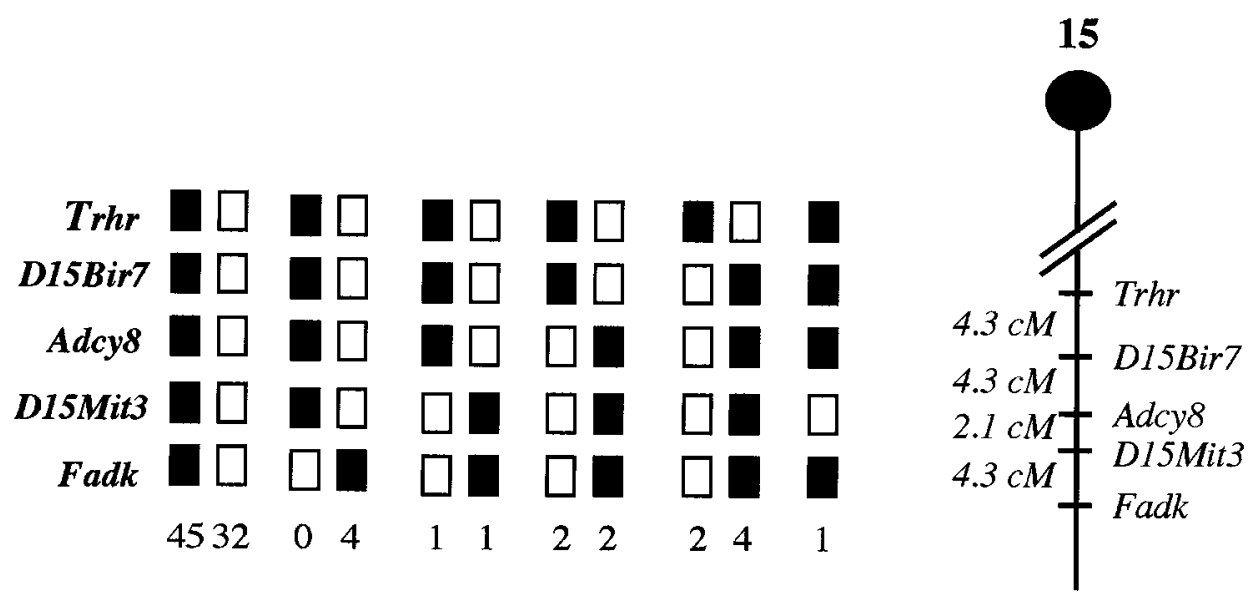

olfactory bulb, lateral septal nuclei, thalamus, and cerebral cortex, (Fig. 7). Positive, but less intense, $\beta$-galactosidase activity was found in the CA1 region of the hippocampus, granule layer of the cerebellum, and habenula. The CA3 region of the hippocampus and a cell layer immediately dorsal to the corpus callosum dem- onstrated $\beta$-galactosidase activity but lacked significant AC8 mRNA by in situ hybridization. We have not yet determined definitively the site of AC8 promoter-driven $\beta$-galactosidase expression within the lung because of significant endogenous $\beta$-galactosidase activity in pulmonary cells and lower AC8 pro- 


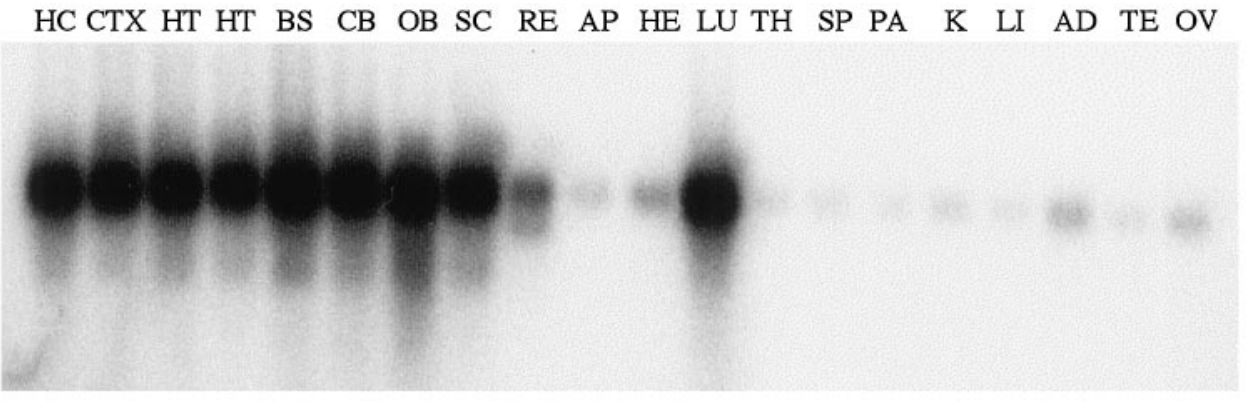

Figure 3. RT-PCR analysis of AC8 gene expression. Shown is autoradiographic detection of the expected $473 \mathrm{bp}$ product from CNS and peripheral sites. Abundant expression was found in all brain regions and in the lung. Hippocampus, $H C$; cerebral cortex, $C T X$; hypothalamus, $H T$, from male and female, respectively; brainstem, $B S$; cerebellum, $C B$; olfactory bulb, $O B$; spinal cord, $S C$; retina, $R E$; anterior pituitary, $A P$; heart, $H E$; lung, $L U$; thymus, $T H$; spleen, $S P$; pancreas, $P A$; kidney, $K$; liver, $L I$; adrenal, $A D$; testis, $T E$; ovary, $O V$.

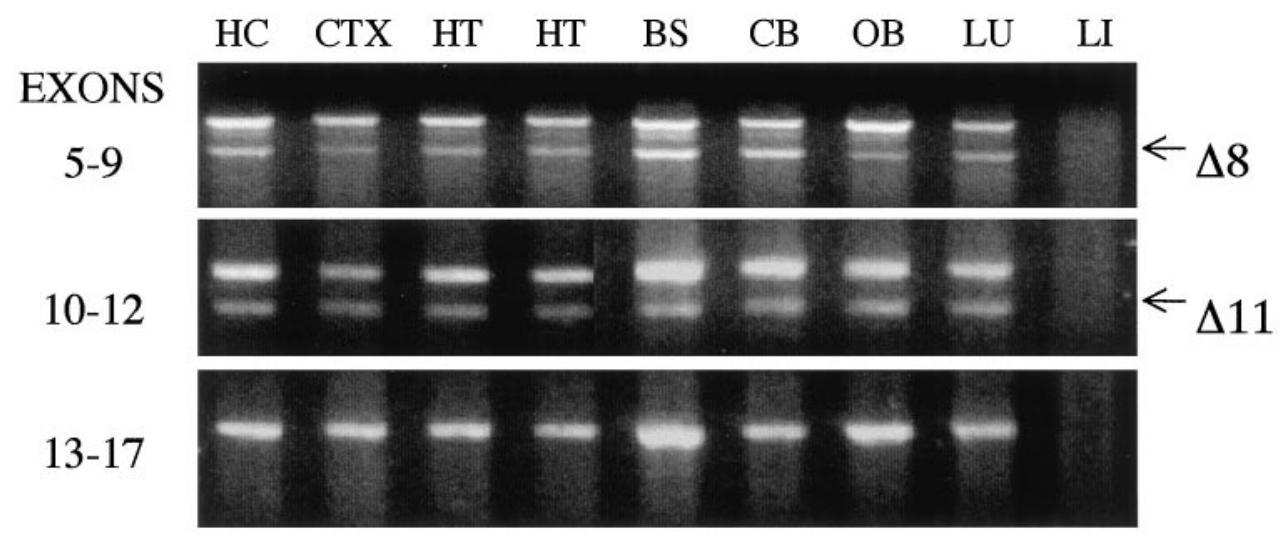

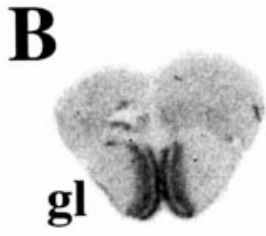

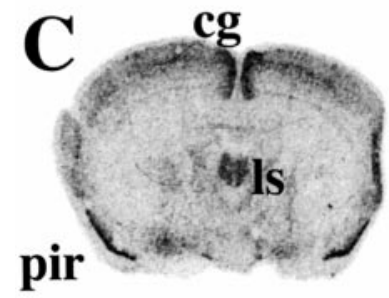

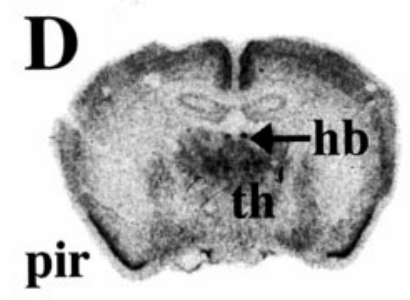

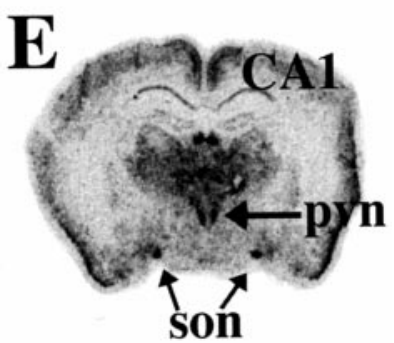

Figure 4. RT-PCR analysis of AC8 splice variants. Products were generated from the following sources of total RNA: hippocampus, $H C$; cerebral cortex, $C T X$; male and female hypothalamus, respectively, $H T$; brainstem, $B S$; cerebellum, $C B$; olfactory bulb, $O B$; lung, $L U$; and liver, $L I$ as a negative control. Amplification used primers from the exons indicated on the left (e.g., primers for the first row cDNAs were from exons 5 and 9). The top band in each panel of ethidium-stained agarose gels represents the expected amplification product for the full-length cDNA. Alternatively spliced products are indicated with an arrow and the exon, which is deleted.

$(\mathrm{cg}) . D$, Coronal section through the hypothalamus, just caudal to section in $C$. In addition to the piriform observed in the habenula $(h b)$ and throughout the thalamus $(t h)$. E. Coronal section through the hypothalamic paraventricular nucleus $(p v n)$. Diff use thalamic hybridization is again observed, with additional hybridization found in the paraventricular nucleus and supraoptic nuclei (son). The CA1 region of the hippocampus hybridizes weakly.

moter activity compared with brain, as suggested by in situ hybridization.

\section{DISCUSSION}

We have found that the AC8 gene consists of 18 exons, which encompass $\sim 200 \mathrm{~kb}$ of mouse genomic DNA on chromosome 15 . The locus we defined is syntenic to human chromosome 8q24 (Stengel et al., 1992), the known location of the human AC8 gene. There are no naturally occurring mouse mutations that map to this region that are suggestive of AC8 deficiency (Rowe et al.,

Figure 5. Localization of AC8 mRNA in brain by in situ hybridization. Shown are representative autoradiograms of slidemounted sections exposed for $14-21 \mathrm{~d}$. $A$, Sagittal section through mouse brain shows most intense hybridization in the olfactory bulb $(o b)$ and thalamus $(t h)$. Positive, but less intense, hybridization is observed in several other regions, including the cerebellum $(c b) . B$, Coronal section through the orbital cortex and olfactory bulb. Hybridization was observed primarily in the periglomerular cells in the glomerular layer $(g l)$, with less intense hybridization also found in the mitral layer. $C$, Coronal section through the anterior hypothalamus. Diff use hybridization was found, with the highest levels of expression in the lateral septal nuclei $(l s)$, piriform cortex ( pir), and cingulate cortex
cortex ( $p i r)$, prominent hybridization is 
Figure 6. Expression of $\beta$-galactosidase activity in AC8 promoter-nuclear $\beta$ galactosidase transgenic mice. $A$, Schematic representation of the transgene. Ten kilobases of the AC8 5'-flanking region extending up to the $X h o \mathrm{I}$ site $(X)$ in the untranslated region of exon 1 (hatched box) is fused to the nuclear $\beta$-galactosidase coding region $(n \beta$-gal $)$. Mouse protamine 1 (stippled box) sequences downstream of the $\beta$-galactosidase termination codon provide an intron and polyadenylation sequences. $B$, In situ hybridization using a radiolabeled AC8 probe reveals silver grain deposition in the piriform cortex after emulsion development. $C$, Histochemical demonstration of nuclear $\beta$-galactosidase activity in the piriform cortex of transgenic mice. The precipitate appears red on darkfield microscopy. D, In situ hybridization with a radiolabeled oxytocin probe demonstrates the position of the supraoptic nucleus. E, In situ hybridization of a radiolabeled AC8 probe to a section adjacent to that shown in Figure $7 D$ reveals AC8 mRNA in the supraoptic nucleus. $F$, Nuclea nucleus of transgenic mice.

Figure 7. Whole-mount histochemical analysis of AC8 promoter-nuclear $\beta$ galactosidase transgenic mice. $\beta$-Galactosidase activity after whole-mount X-gal staining appears as a blue-green precipitate. Endogenous $\beta$-galactosidase activity was limited to the choroid plexus, where staining was cytoplasmic rather than nuclear. $A$, Parasagittal section of transgenic brain. Robust expression is found in the olfactory bulb $(o b)$, with less intense staining in the thalamus $(t h)$, cortex, and cerebellum $(c b)$. $B$, Coronal section through the olfactory bulb. Nuclear staining is demonstrated in the periglomerular cells of the glomerular layer $(\mathrm{gl})$ and in the mitral layer $(\mathrm{ml}) . C$, Coronal section through the anterior hypothalamus. Piriform cortex ( pir), lateral septal nuclei $(l s)$, and cells in defined layers of the cerebral cortex (including immediately adjacent to the corpus callosum) demonstrate transgene expression. $D$, Coronal section through the midhypothalamus. $\beta$-Galactosidase activity was found in anterodorsal, anteroventral, and anteromedial thalamic nuclei $(t h)$, the thalamic anterior paraventricular nucleus ( $p v a)$, and the hypothalamic paraventricular nucleus ( $p v n)$, as well as the cerebral cortex. $E$, Coronal section through the posterior hypothalamus. X-gal staining is demonstrated in the arcuate nucleus of the hypothalamus (an), thalamic lateral geniculate nucleus (lgn), hippocampal CA3, and, to a lesser extent, CA1 regions. $F$, Parasagittal section through the cerebellum. Arrow demonstrates stained nuclei restricted to the granule layer.
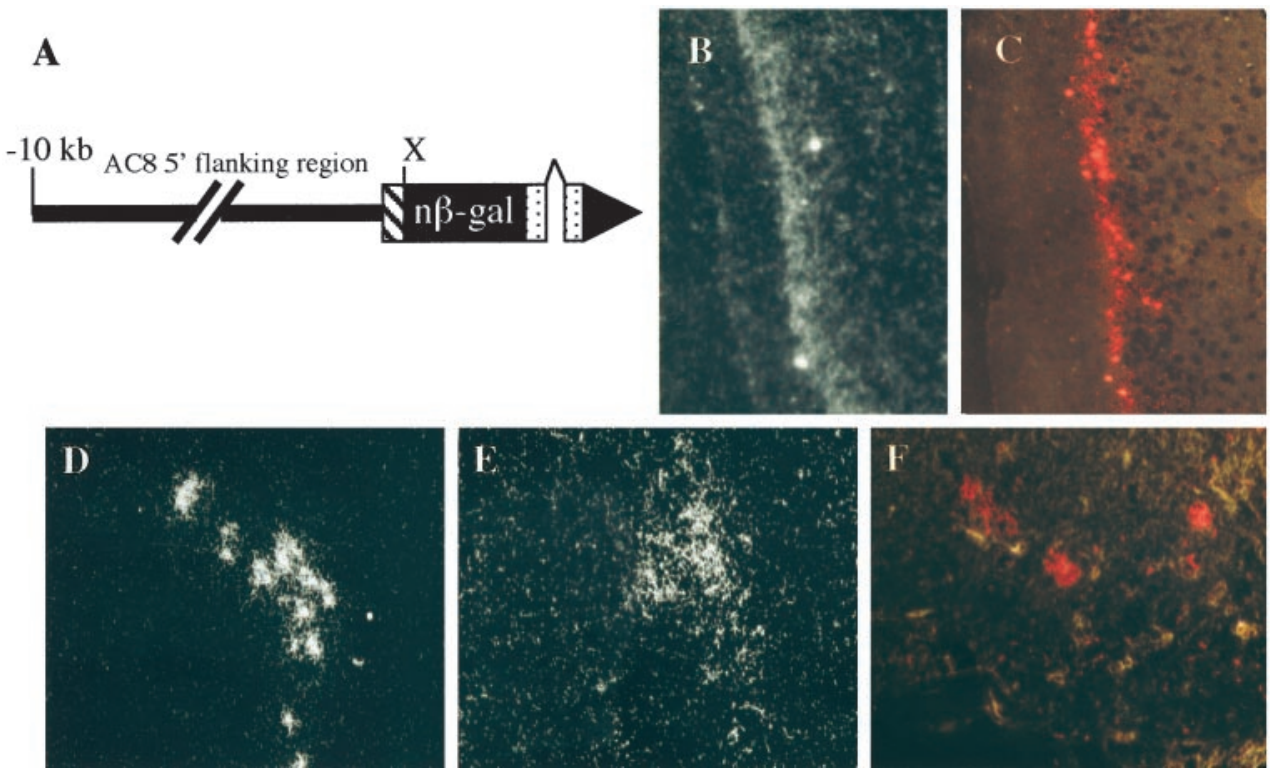

$\beta$-galactosidase activity, as shown by the red nuclei under dark-field microscopy, is present in the supraoptic

A
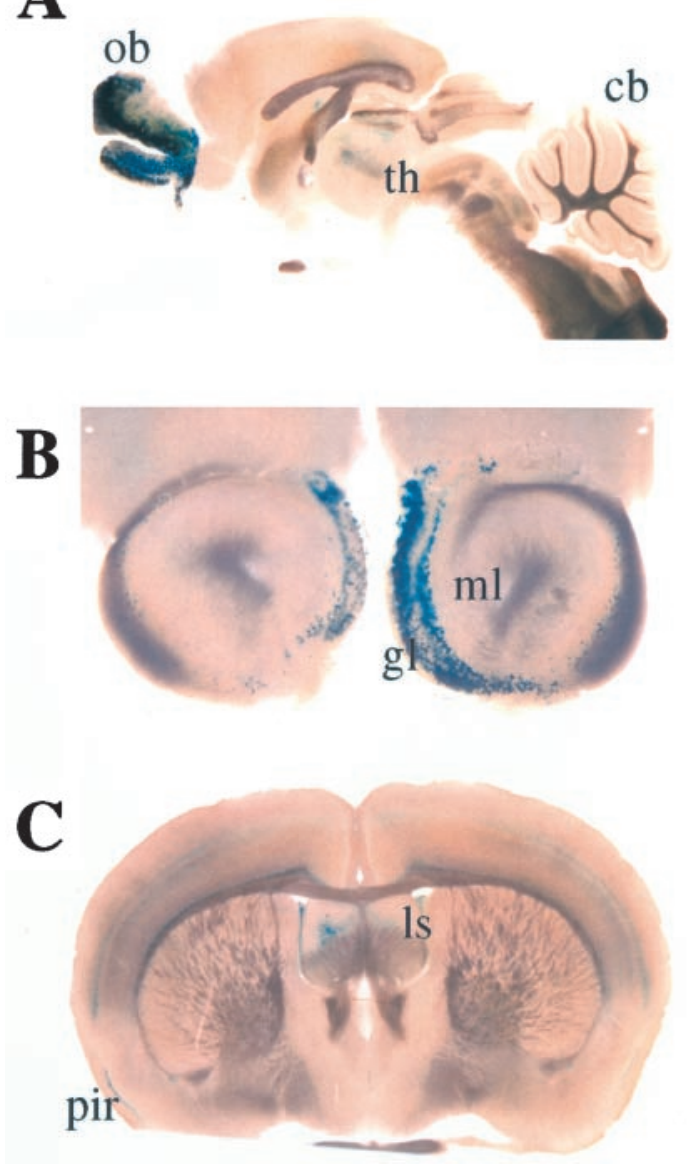

D
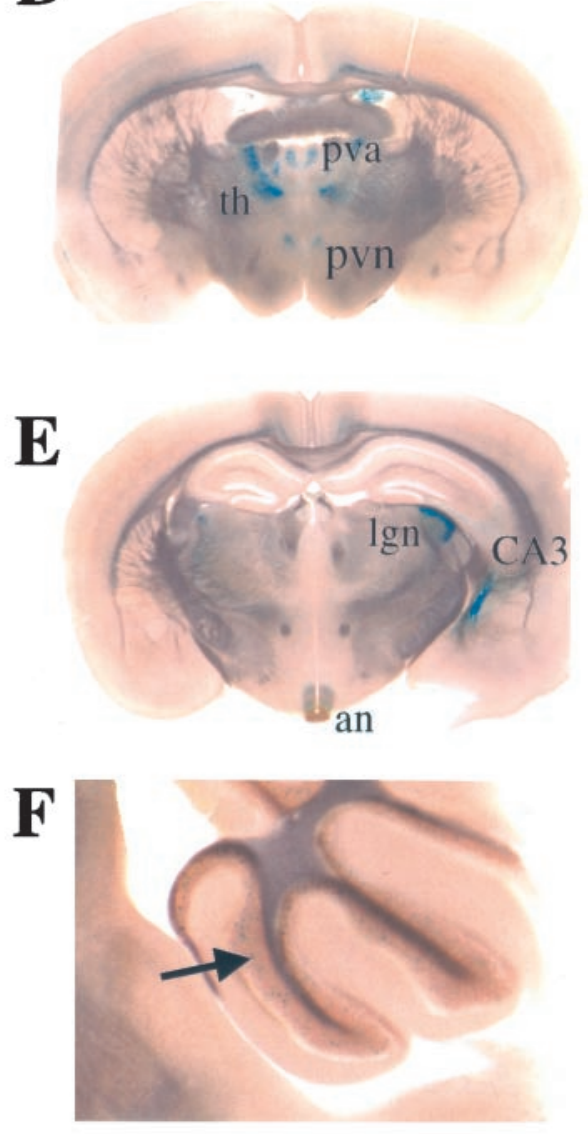

forms in ratios that did not significantly vary depending on location. Although no significant differences in the pattern of expression of each of the splice variants were apparent in different brain regions, we have not excluded differences in the ratios of the variants within certain nuclei.
The 5' end of the mouse AC8 mRNA, as determined by $\mathrm{RACE}$, implicated a region $\sim 2 \mathrm{~kb}$ upstream of the translation initiation site and $1 \mathrm{~kb} 5^{\prime}$ of the rat AC8 cDNA (Cali et al., 1994) as the transcription initiation region. This very long untranslated leader is highly conserved in comparison with the human cDNA 
(Defer et al., 1994) and suggests a role in posttranscriptional regulation or localization as an important component of AC8 expression. The promoter region is without a canonical TATA sequence but does contain a cAMP response element. This supports the recent finding that induction of AC8 expression in the locus coeruleus during chronic administration of morphine (Matsuoka et al., 1994; Lane-Ladd et al., 1997) is attentuated by injection of cAMP response element-binding protein antisense oligonucleotides (Lane-Ladd et al., 1997).

To address most sensitively the localization and regulation of the AC8 gene as evidence for nonredundant function with the other AC isoforms, we used two complementary methods. First, high-stringency in situ hybridization localized expression of the endogenous AC8 mRNA. Second, the putative transcription regulatory region of the AC8 gene determined the pattern of expression of a nuclear $\beta$-galactosidase reporter gene. The pattern of expression of the AC8 promoter-nuclear $\beta$-galactosidase reporter gene was in quite close agreement with the pattern we demonstrated by in situ hybridization for the endogenous AC8 gene, further implicating the region identified by RACE as the transcription initiation site. The most robust expression of the transgene was present in olfactory bulb and thalamus, with concordant expression compared with AC8 mRNA in most other sites, including the CA1 region of the hippocampus, granule layer of the cerebellum, cerebral cortex, piriform cortex, and the paraventricular, supraoptic, and arcuate hypothalamic nuclei. Despite high-level expression of AC8 mRNA in the habenula, relatively low $\beta$-galactosidase activity was observed at this site. Conversely, $\beta$-galactosidase activity was present adjacent to the corpus callosum and in the CA3 region of the hippocampus, which lacked detectable AC8 mRNA. This could reflect differences in localization of cytoplasmic AC8 mRNA versus a nuclear $\beta$-galactosidase protein. Alternatively, DNA regulatory sequences necessary for expression or repression in specific brain sites may not be contained within our transgene. The overall pattern of AC8 mRNA expression we find by in situ hybridization is primarily in agreement with previous reports (Matsuoka et al., 1992, 1994; Cali et al., 1994). Our results differ from previous studies that suggested high-level expression of AC8 mRNA within the hippocampus (Matsuoka et al., 1992, 1994; Cali et al., 1994) and cerebellum (Matsuoka et al., 1992, 1994). These studies used less stringent hybridization conditions to accommodate hybridization by oligonucleotide or cross-species templates and did not have the negative control of AC8-deficient mice to most rigorously assess specificity of hybridization. Because of the low abundance of AC8 overall, our transgenic reporter lines should facilitate studies evaluating neuropeptide colocalization with AC8 and transcriptional modulation in response to physiological and behavioral stimuli.

The distribution of AC8 compared with the other calciumstimulated adenylyl cyclases is unique with respect to its synthesis in thalamus, habenula, olfactory bulb, and the paraventricular and supraoptic hypothalamic nuclei. This hypothalamic distribution strongly suggests a role for AC8 in modulation of the stress response, lactation, or water metabolism. Moreover, the colocalization of AC8 and $\mu$-opioid receptor in the habenula and thalamic nuclei (Bunzow et al., 1995), along with the augmentation of AC8 transcription during chronic morphine administration (Matsuoka et al., 1994; Lane-Ladd et al., 1997), suggests a central role for AC8 in opioid tolerance and withdrawal. Functional analyses of AC8-deficient, and combined AC1- and AC8-deficient mice, should reveal the unique and redundant roles of these calcium-stimulated isoforms in neuronal function and physiology.

\section{REFERENCES}

Bae DS, Schaefer ML, Partan BW, Muglia L (1996) Characterization of the mouse DAX-1 gene reveals evolutionary conservation of a unique amino-terminal motif and widespread expression in mouse tissue. Endocrinology 137:3921-3927.

Barnes WM (1994) PCR amplification of up to $35 \mathrm{~kb}$ DNA with high fidelity and high yield from $\lambda$ bacteriophage templates. Proc Natl Acad Sci USA 91:2216-2220.

Bonnerot C, Rocancourt D, Briand P, Grimber G, Nicolas JF (1987) A $\beta$-galactosidase hybrid protein targeted to nuclei as a marker for developmental studies. Proc Natl Acad Sci USA 84:6795-6799.

Bunzow JR, Zhang G, Bouvier C, Saez C, Ronnekleiv OK, Kelly MJ, Grandy DK (1995) Characterization and distribution of a cloned rat $\mu$-opioid receptor. J Neurochem 64:14-24.

Cali JJ, Zwaagstra JC, Mons N, Cooper DM, Krupinski J (1994) Type VIII adenylyl cyclase. A $\mathrm{Ca}^{2+} /$ calmodulin-stimulated enzyme expressed in discrete regions of rat brain. J Biol Chem 269:12190-12195.

Cali JJ, Parekh RS, Krupinski J (1996) Splice variants of type VIII adenylyl cyclase. Differences in glycosylation and regulation by $\mathrm{Ca}^{2+} /$ calmodulin. J Biol Chem 271:1089-1095.

Chomczynski P, Sacchi N (1987) Single step method of RNA isolation by acid guanidinium thiocyanate-phenol-chloroform extraction. Anal Biochem 162:156-159.

Cooper DM, Mons N, Karpen JW (1995) Adenylyl cyclases and the interaction between calcium and cAMP signalling. Nature 374: 421-424.

Copeland NG, Jenkins NA (1991) Development and applications of a molecular linkage map of the mouse genome. Trends Genet 7:113-118.

Davis RL, Cherry J, Dauwalder B, Han PL, Skoulakis E (1995) The cyclic AMP system and Drosophila learning. Mol Cell Biochem 149-150:271-278.

Defer N, Marinx O, Stengel D, Danisova A, Iourgenko V, Matsuoka I, Caput D, Hanoune J (1994) Molecular cloning of the human type VIII adenylyl cyclase. FEBS Lett 351:109-113.

Feinstein PG, Schrader A, Bakalyar HA, Tang WJ, Krupinski J, Gilman AG, Reed RR (1991) Molecular cloning and characterization of a calcium-insensitive adenylyl cyclase (type II) from rat brain. Proc Natl Acad Sci USA 88:10173-10177.

Hogan B, Beddington R, Constantini F, Lacy E (1994) Manipulating the mouse embryo: a laboratory manual, Ed 2. Cold Spring Harbor, NY: Cold Spring Harbor Laboratory.

Krupinski J, Lehman TC, Frankenfield CD, Zwaagstra JC, Watson PA (1992) Molecular diversity in the adenylyl cyclase family. Evidence for eight forms of the enzyme and cloning of type VI. J Biol Chem 267:24858-24862.

Lane-Ladd SB, Pineda J, Boundy VA, Pfeuffer T, Krupinski J, Aghajanian GK, Nestler EJ (1997) CREB (cAMP response element-binding protein) in the locus coeruleus: biochemical, physiological, and behavioral evidence for a role in opiate dependence. J Neurosci 17:7890-7901.

Levin LR, Han PL, Hwang PM, Feinstein PG, Davis RL, Reed RR (1992) The Drosophila learning and memory gene rutabaga encodes a $\mathrm{Ca}^{2+}$ /calmodulin-responsive adenylyl cyclase. Cell 68:479-489.

Matsuoka I, Giuili G, Poyard M, Stengel D, Parma J, Guellaen G, Hanoune J (1992) Localization of adenylyl and guanylyl cyclase in rat brain by in situ hybridization: comparison with calmodulin mRNA distribution. J Neurosci 12:3350-3360.

Matsuoka I, Maldonado R, Defer N, Noel F, Hanoune J, Roques BP (1994) Chronic morphine administration causes region-specific increase of brain type VIII adenylyl cyclase mRNA. Eur J Pharmacol 268:215-221.

Mons N, Cooper DM (1994) Adenylyl cyclase mRNA expression does not reflect the predominant $\mathrm{Ca}^{2+} /$ calmodulin-stimulated activity in the hypothalamus. J Neuroendocrinol 6:665-671.

Rowe LB, Nadeau JH, Turner R, Frankel WN, Letts VA, Eppig JT, Ko MSH, Thurston SJ, Birkenmeier EH (1994) Maps from two interspecific backcross DNA panels available as a community genetic mapping resource. Mamm Genome 5:253-274. 
Simmons DM, Arriza JL, Swanson LW (1989) A complete protocol for in situ hybridization of messenger RNAs in brain and other tissues with radiolabeled single-stranded RNA probes. J Histotechnol 12:169-181.

Stengel D, Parma J, Gannage MH, Roeckel N, Mattei MG, Barouki R, Hanoune J (1992) Different chromosomal localization of two adenylyl cyclase genes expressed in human brain. Hum Genet 90:126-130.

Sunahara RK, Dessauer CW, Gilman AG (1996) Complexity and diversity of mammalian adenylyl cyclases. Annu Rev Pharmacol Toxicol 36:461-480.

Wu ZL, Thomas SA, Villacres EC, Xia Z, Simmons ML, Chavkin C, Palmiter RD, Storm DR (1995) Altered behavior and long-term potentiation in type I adenylyl cyclase mutant mice. Proc Natl Acad Sci USA 92:220-224.
Xia Z, Refsdal CD, Merchant KM, Dorsa DM, Storm DR (1991) Distinct patterns for the distribution of mRNA for the calmodulinsensitive adenylyl cyclase in rat brain: expression in areas associated with learning and memory. Neuron 6:431-443.

Xia Z, Choi EJ, Wang F, Storm, DR (1992) The type III calcium/ calmodulin-sensitive adenylyl cyclase is not specific to olfactory sensory neurons. Neurosci Lett 144:169-173.

Xia Z, Choi EJ, Wang F, Blazynski C, Storm DR (1993) Type I calmodulin-sensitive adenylyl cyclase is neural specific. J Neurochem 60:305-311.

Xia Z, Choi E-J, Storm DR, Blazynski C (1995) Do the calmodulinstimulated adenylyl cyclases play a role in neuroplasticity? Behav Brain Sci 18:429-440. 